\title{
Exploring and Developing an Industrial Automation Acceptance Model in the Manufacturing Sector Towards Adoption of Industry4.0
}

\author{
Muhammad Ramzul Abu Bakar (0000-0001-9245-199X), Noor Afiza Mat Razali (0000-0001-5149-3907), Muslihah \\ Wook (0000-0002-2075-4753), Mohd Nazri Ismail (0000-0002-7781-6767), Tengku Mohd Tengku Sembok (0000- \\ 0002-0913-6540) \\ Faculty of Defence Science and Technology, National Defence University of Malaysia, Kuala Lumpur, Malaysia. \\ E-mail:3181083@alfateh.upnm.edu.my,noorafiza@upnm.edu.my
}

Technological progress in the 21st century has catalysed the industrial revolution (Industry 4.0) following the development of multiple new industrial automation technologies in the manufacturing sector. Regardless, past research indicated the unsuccessful attempts in adopting Industry 4.0 technologies among manufacturing organisations. Undoubtedly, the operationalisation of Industry 4.0 in manufacturing proved challenging as organisations were required to evaluate various aspects for effective implementation. Thus, a sound understanding of constructs concerning employees' acceptance and readiness levels towards novel automation technologies was required. Hence, this study aims to explore, develop, and validate the suggested conceptual framework by integrating the Technology Acceptance Model (TAM) and Technology Readiness Index (TRI) with Exploratory Factor Analysis (EFA). The EFA process was the first crucial step in ensuring the internal consistency and stability of the instrument across the sampling population. Consequently, the research outcome potentially enabled the manufacturing sector to identify and comprehend the key determinants in designing industrial automation technologies. This study also contributed to knowledge on technology acceptance by synthesizing TAM 3 and TRI 2.0 theories, thus constructing a new TAM in manufacturing.

Keywords: Industrial automation, Manufacturing, TAM, TRI, EFA

\section{Introduction}

The past three industrial revolutions have transformed the manufacturing sector by incorporating mechanisation, electricity, and information technology (IT) [1]. Specifically, technological progress and futuristic manufacturing systems led to the conception of Industry $4.0[2,3]$. The term was first coined by German researchers in 2015 and has since drawn academicians' and industry players' interest over the past decades. Industry 4.0 was catalysed by the astute digitalisation of efficient manufacturing systems with four focal drivers: the Internet of Things, Industry Internet of Things (IIoT), smart manufacturing, and cloudbased manufacturing $[4,5]$. Additionally, the industrial revolution would convert production facilities into a fully-integrated, mechanised, and optimised production flow following the nine Industry 4.0 pillars [6]. One of the pillars included 'autonomous robotic' or 'industrial automation'. Industrial automation employed flexible control systems to perform complex tasks autonomously, effectively, and accurately in production lines [3] daily through systemised self-learning [6].

Industry 4.0 also integrated new equipment, knowledge, concepts [7], standards, interconnections, technical aid, information transparency, and decentralised decision-making [8] within the organisation. The primary challenges in manufacturing companies concerned organisational flexibility and agility in line with the dynamic market trends [9] and the timely need to adapt to technological innovations and boost technological efficiency [10]. Furthermore, the manufacturing industry must demonstrate more integration and agility in responding to industrial changes and adopting novel technologies in line with industrial requirements. The recent trends in manufacturing involved mass customisation, personalised products, and versatile product designs [11] that needed advanced equipment and technologies. Regardless, the occurrence of any technological shifts in manufacturing organisations was complex and potentially risked the operationalisation of the entire business model.

Business model characteristics required serious consideration in innovating new technologies. It was highly challenging for the manufacturing industry to simultaneously change both the business model and relevant technologies [12]. Overall, the technological advancements in manufacturing significantly affected the organisations involved. Thus, employees' perceptions of the industrial changes should also be regarded in planning organisational strategies for structural changes in the operative design of organisational systems [13]. A timely response to the technological shifts 
through Industry 4.0 ensured organisational sustenance and established a strategy for the future needs of manufacturing organisations [14]. Nevertheless, Industry 4.0 remains a novel phenomenon at the preliminary stage and is yet to be widely acknowledged except by a few experts. Unsurprisingly, research on the current adoption of Industry 4.0 technologies remains lacking.

The relationship between industrial characteristics and the adoption of Industry 4.0 is still relatively unknown [15]. Thus, manufacturers needed to comprehend the adoption factors in designing and constructing appropriate decision-making processes to analyse the adoption strategies and understand the acceptance and resistance factors involved. Industrial adoption at both individual and organisational levels was vital for the successful operationalisation of Industry 4.0. Government bodies should also be cognizant of the acceptance process outcomes in decisionmaking, the implementation of Industry 4.0, and incentive adjustments. The rapid technological development of Industry 4.0 simultaneously accelerated the mechanised pace in manufacturing and improved the industrial automation level, thus resulting in a closedloop information flow at the factory level [16].

Undoubtedly, a holistic implementation of Industry 4.0 in the manufacturing industry was challenging owing to the various organisational aspects [6]. Past studies indicated that the primary barriers in actualising Industry 4.0 involved advanced automation, virtualisation, and flexibilisation. Nonetheless, the manufacturing organisations that succeeded in operating highly complex technologies achieved a better competitive advantage [17]. Furthermore, the lack of digitalisation and knowledge on the benefits of implementing Industry 4.0 tools at the organisational level hindered the manufacturing industry from initiating technological adoptions [18, 61]. Another obstacle faced by the manufacturing industry, particularly for Small and Medium Enterprises (SMEs), involved big-scale financial investments and expenditure to computerise the manufacturing process through new software and equipment installations [18]. Organisations would also need to provide adequate staff training to efficiently operate the tools and deliver optimal usage corresponding to the Industry 4.0 pillars [1].

Following the scepticism in combining new technologies in organisations, the crucial components involving employees' and other parties' acceptance and readiness levels in integrating new automation technologies required serious consideration. Multiple studies in recent years gauged and elaborated on the factors influencing technological usage and acceptance [19, 21]. For example, TAM proved to be a vital model for scholars to identify and predict human behaviour towards the possible acceptance or rejection of novel technologies [20], whereas TRI emphasised individuals' positive and negative readiness towards technological usage. As such, this study recommended a conceptual model that integrated technological readiness and acceptance constructs in manufacturing, specifically regarding the implementation of automation technology under TAM and TRI. Moreover, the model empirically contributed to a sound understanding of technology acceptance in Industry 4.0 among manufacturing organisations.

\section{Theoretical Analysis}

\subsection{Industrial Automation}

Manufacturing processes could be optimised with the congruent integration of industrial robots and human operators. For example, industrial robots were capable of managing high payloads in a faster and more efficient manner without fatigue. Although the physical human capacity and cognitive reasoning required in multiple production activities were irreplaceable by robots, the stamina and repeatability required in less-skilled and hazardous tasks could still be provided through artificial intelligence. Hence, the integration of employees' deductive and cognitive abilities with the speed, accuracy, and strength of industrial robots was deemed logical.

Employees could execute tasks requiring judgment and versatility, whereas industrial robots could conduct tasks, particularly hazardous activities, that require accuracy, speed, and strength. In this vein, the human-robot collaboration (HRC) was established in the manufacturing context. Additionally, recent technological progress has led to the adoption of more comprehensive health and safety standards that allowed humans to safely engage with robots [22]. The industrial HRC concept is gaining importance to increase productivity and efficiency in manufacturing. Nevertheless, safety features are vital in HRC and require complex planning and strategizing following industrial health and safety standards. Hence, the organisational factors affecting individuals in manufacturing needed to be explored to consider the advantages of industrial HRC. For example, Charalambous, Fletcher and Webb attempted to identify the core human factors in organisations to successfully implement industrial HRC using an industrial exploratory case study [23].

Past studies outlined the complexity and reliability of human-automation interactions in the cognitive engineering field. Given the lack of focus on human-automation decision-making compatibilities, incongruencies between human and automation problem-solving styles (in adopting industrial automation at the factory level) could become a critical issue in the Industry 4.0 context. Research on automation acceptance primarily emphasised the identification and prevention 
of inappropriate automation usage, often categorised as the misuse (overreliance) or disuse (under reliance) of automation [24].

Relevant works of literature generally regarded the incorporation of human capacities and autonomous technologies in high-risk, evolving, and intricate ecosystems [18, 25], such as aircraft carriers, nuclear power plants, space shuttle operations, firefighting, and heavy manufacturing such as automotive industry $[26,27,62,63]$. Several influential elements concerning the choice of automation used in manufacturing involved automation trust, self-confidence in manual performance, perceived risk, and fatigue. In contrast, the human elements included innovation, efficient communication, competency, software-based training, collaboration, and continuous digital awareness (specifically automation attitude, trust, workload, and complexities, the perceived risk of automation use, and perceived automation reliability) $[18,28,31]$.

In transforming Industry 4.0, manufacturing organisations were required to gauge the employees' views on a revolutionised system: organisational reforms were highly risky, did not guarantee success, and significantly impacted manufacturing companies. The high-risk factors inevitably led to employees' anxiety and confusion and indicated serious morale issues within the organisation. Employee morale was inextricably linked to organisational trust and highly affected the chances of success following organisational changes or innovations [32]. Therefore, the top management in organisations needed to actively address employees' concerns on the Industry 4.0 benefits. In this regard, employees' training and development should complement Industry 4.0-oriented competencies and skills, such as data analytics, IT, software, and the intricacies of human-machine interactions [33]. Besides, employees' commitment to systemic changes following a new operational paradigm was enhanced by duly addressing the transition and preparation phases without undermining communication and training prerequisites. Consequently, the communicating issues and potential misunderstandings from incomplete project implementations and over-expectations in organisations could be minimised [34].

\subsection{The TAM}

The development of TAM in enabling individuals to predict acceptance and technological levels [35] has gained importance over the past two decades. Specifically, the widely-adopted theory was extensively used to explain and gauge systemic usage in several recently-developed TAM-oriented models. As an influential study model, TAM was developed by Davis [36] to examine the determinants of technological acceptance and predict individuals' intentions and acceptance of technological use. For example, TAM consisted of two determinants: perceived ease of use
(PEoU) and perceived usefulness (PU). Specifically, PU denoted the extent to which an individual believed that employing a particular information system or technology elevated work performance. In contrast, PEoU denoted the extent to which an individual believed that utilising a particular information system or technology waived human effort. Hence, PEoU and PU could positively influence users' attitudes, intentions and acceptance levels towards information systems. In this vein, PEoU could positively influence PU, whereas both PEoU and PU were influenced by external variables [36].

The TAM 3 is an extension of TAM established by Venkatesh and Bala [35] to measure individuals' technological acceptance and adoption using specific constructs. For example, TAM 3 theorised novel relationships between (i) PU and PEoU, (ii) computer anxiety (CA) and PEoU, and (iii) PEoU and behavioural intentions (BI). The theoretical foundation in TAM3 outlined four primary factors that explicitly affected technology acceptance: social influences, individual differences, system characteristics, and facilitating conditions. Following Venkatesh and Bala [35], the four factors had varying impacts on both PU and PEoU constructs.

Based on the aforementioned factors, TAM determinants were categorised in groups as no cross-overs among the determinants were deemed possible. The separation denoted that the determinants influencing PU could not influence PEoU and vice versa. Besides, social influence factors demonstrated the importance of an individual's belief in system usage. Specifically, system characteristics were demonstrated through cognitive instrumental processes and reflected individuals' beliefs on the advantages of technological usage. The individual difference generally illustrated individuals' beliefs towards computers and computer utilisation. Meanwhile, facilitating conditions indicated the perception of external control (PEC) determinants regarding access to technical support and resources [35].

Venkatesh and Bala [35] also inserted 'Experience' and 'Voluntariness' as the moderators potentially influencing PU, PEoU, and BI (see Figure 1). To date, TAM has been modelled by many researchers to hold more superiority than other models, such as the Theory of Reasoned Action and Theory of Planned Behaviour in explaining people's novel technological adoption intentions [20, 37, 38].

\subsection{The TRI}

In Parasuraman[39], technology played a significant role at organisational and individual levels. Specifically, technology readiness defined people's eagerness to accept, adopt, and incorporate technological changes on a personal and professional basis. In this vein, TRI measured people's tendency to accept and 
utilise modern technologies [39]. The four TRI dimensions are listed as follows [39, 40]:

- Optimism (OP): positive approaches at individual and organisational levels following new technological usage;

- Innovativeness (IN): the IN levels accepted by individuals and organisations in developing cutting-edge technology;

- Discomfort (DS): a negative response to technological changes. Some people experienced DS due to the complications and immediacy of technological changes. The dimension was a negative factor for companies, particularly small-scale companies with limited funds. Organisational management could also face high DS levels in adopting or implementing novel technologies;

- Insecurity (IS): scepticism or distrust towards technology, thus resulting in people's IS. Organisations could also observe IS in new technological implementation owing to high cost and ambiguities in long-term technological sustenance.

Following Parasuraman [39, 40], OP and IN were the two most positive technological drivers in introducing a new model at individual and organisational levels. Meanwhile, DS and IS were negative elements that may hinder the overall acceptance rate of advanced technologies among individuals and organisations. Consequently, TRI was often selected based on the aforementioned factors to suit the psychological assessment of individuals and companies in rejecting or accepting new technologies. Initially, TRI was employed to measure customers' technological readiness towards technology-based services (financial and online services) $[39,40]$.

\subsection{The TRAM}

The integration of TRI and TAM resulted in the Technology Readiness and Acceptance Model (TRAM) with resounding popularity in the past decade. Notably, Lin et al. [41] indicated high correlations between TRI attributes towards the PU and PEoU of TAM. Similar studies by Hallikainen and Laukkanen[42], Shin and Le [43], Larasati et al. [44], and Yi et al. [45] supported TRAM. Furthermore, TRAM emphasised the mapped attributes of the personality-specific TRI construct and the system-specific TAM construct. Past studies revealed that personality construct could affect people's technological interactions, experiences, and usage. For example, Yi's et al. study implied that both TRI and TAM were designed to outline individual technology acceptance. Specifically, TRI emphasised individuals' general technological perspective, whereas TAM entailed people's system-specific perception of technological acceptance[36].

Although the original TAM was established in 1989 and TRI was established in 2000, both theories are still valid and recently there are still numerous researchers are using TAM and TRI models to measure the user acceptance and readiness of new emerging technologies on various applications such as acceptance of Airbnb sharing accommodation [64], online learning system [65], facial recognition payment [66], e-learning adoption [67], students' use of Zoom application [68], online food delivering ordering services [69], adoption of self-service technology [70] and virtual reality in fashion retailing [71].

It should be emphasized that even though the TAM, TRI and TRAM models used are similar in term of the constructs, there was still a lack of researches in the area of the manufacturing sector. Hence in this paper, our novelty is to study the industrial automation technology level of acceptance and readiness in the manufacturing sector. The scope of the study and target respondents are the employees that have experience in adopting new technology in the manufacturing facilities. With this model, we are expecting to contribute to the new knowledge of the level of acceptance of Industry4.0's technology adoption in the manufacturing sector.

\section{Proposed Conceptual Model and Hypo- thesis}

Based on the literature review, this research proposed the incorporation of TAM 3 constructs and TRI 2.0 into the Automation Acceptance Model as the research conceptual framework (see Figure 1). The TAM 3 constructs included Job Relevance (JR) for System Characteristic, Computer Self-Efficacy (CSE) and CA for Individual Difference, and PEC for Facilitating Conditions. The JR construct was selected to indicate an individual's trust level towards automation technology in increasing work improvement and positively influencing PU [35].

Meanwhile, CSE denoted computer-based competencies to demonstrate how the employees' competencies influenced the acceptance and readiness of automation technology. The CA construct was included to examine how individuals perceived technological usage, particularly automation technology. The PEC construct was also examined. Before implementing automation technology, undivided organisational support was vital to ensure employees' technological acceptance and readiness. The attributes were then mapped to PEoU as it was proven to significantly influence behaviour [35]. 
Although TAM 3 and TRI 2.0 could be utilised to predict technological adoption, the core distinction between both theories indicated that TAM $3 \mathrm{em}-$ ployed system-specific observations to gauge technological adoption. On the other hand, TRI 2.0 emphasised individuals' overall dispositions that influenced the intentions to use a product. Thus, this study integrated both TAM3 and TRI 2.0 to examine employees' psychological and cognitive traits, such as PU in gauging acceptance intentions regarding Industry 4.0. Despite the TRI-TAM integration into one model in past studies, very few combined the latest versions of both theories in recommending a new technology adoption model.

Regarding TRI 2.0, the OP, IN, DS, and IS constructs were mapped to both PU and PEoU as emotions potentially influenced usage behaviour Yi et al. [42], [44, 45]. Figure 2 presents the mapping of TAM and TRI construct details and the development of the Automation TAM. The study data would then be collected to identify the acceptance and readiness levels towards the operationalisation of automation technology following the study hypotheses. Several study hypotheses were constructed in line with the conceptual framework to understand the relationships between variables.

For example, JR provided insights into users' technology familiarity levels concerning task performance. Owing to various working environments, users developed multiple expectations following technological usage. Several studies affirmed that JR was a significant PU predictor $[46,48]$. Hence, the study hypothesis was developed as follows:

H1:JR has a positive and significant effect on PU.

The OP construct measured individuals' perception of specific technologies [42]. A technology optimist would expect more benefits from technological adoptions, such as flexibility, increased control, and more productivity [39]. Hence, innovation visionaries were more inclined to be optimistic regarding novel technologies and less inclined to be sceptical, consequently adopting new technologies in advance. As such, the following hypotheses were developed:

H2:OP has a positive and significant effect on PU. H3:OP has a positive and significant effect on PEoU.

Essentially, IN was described as the pioneer in technological use and a contributing factor in technological adoption. Hence, individuals with higher IN traits possessed fundamental motives in utilising or trying new technologies [45]. Consequently, IN affected both PU and PEoU [49]. Following the discussion above, the following hypotheses were developed:
H4:IN has a positive and significant effect on PU. H5:IN has a positive and significant effect on PEoU.

The DS construct was described as a sense of inundation following the lack of control in utilising unknown technology [50]. Individuals overwhelmed by novel technologies worried that the tools or innovations were inappropriate and risky [50]. The construct was relevant to anxieties caused by new technologies and negatively influenced PEoU [51] and PU [52]. Hence, the following hypotheses were developed:

H6:DS has no significant effect on PU.

H7:DS has a negative and significant effect on PEoU.

The IS construct denoted individuals' scepticism or cynicism in the accurate functioning of novel ideas or technologies [39]. Individuals with high IS levels generally possessed little confidence in the security features of new technologies and were concerned with the potential risks involved [39]. Previous findings affirmed that risk-oriented perceptions would affect PU and PEoU [53]. As such, the following hypotheses were developed:

H8:IS has a negative and significant effect on PU.

H9: IS has a negative and significant effect on PEoU.

Fundamentally, CSE enabled individuals to comprehend a novel idea or technology and the success levels in technological assessment [35]. It was observed that CSE positively influenced the usage of new technology [35]. Based on the discussion above, the following hypothesis was developed:

H10: CSE has a positive and significant effect on PEoU.

The apprehensions and fears arising from the complications in technology-human interactions could trigger various destructive emotions, such as technological usage anxiety [35]. Consequently, technological ambiguities and fear of failure would lead to a negative perception of novel ideas and influence individual decisions [35]. Hence, the following hypothesis was developed:

H11: CA has a negative and significant effect on PEoU.

The PEC construct was defined as individuals' perception of accessibility concerning technology and knowledge, sufficient resources, and skills proficiency in implementing new technologies [35]. Consequently, adequately-skilled individuals with access to relevant 
resources found it easier to accept ambiguous tasks and was willing to accept new ideas. Thus, the following hypothesis was developed:

H12: PEC has a positive and significant effect on PEOU.
Past research indicated that individuals who adapted to a system experienced enhanced work performance and individual lifestyles. Hence, PU was found to be a significant determinant in new technological adoptions [35]. In this vein, individuals observed that a system could potentially improve the overall performance of routine tasks.

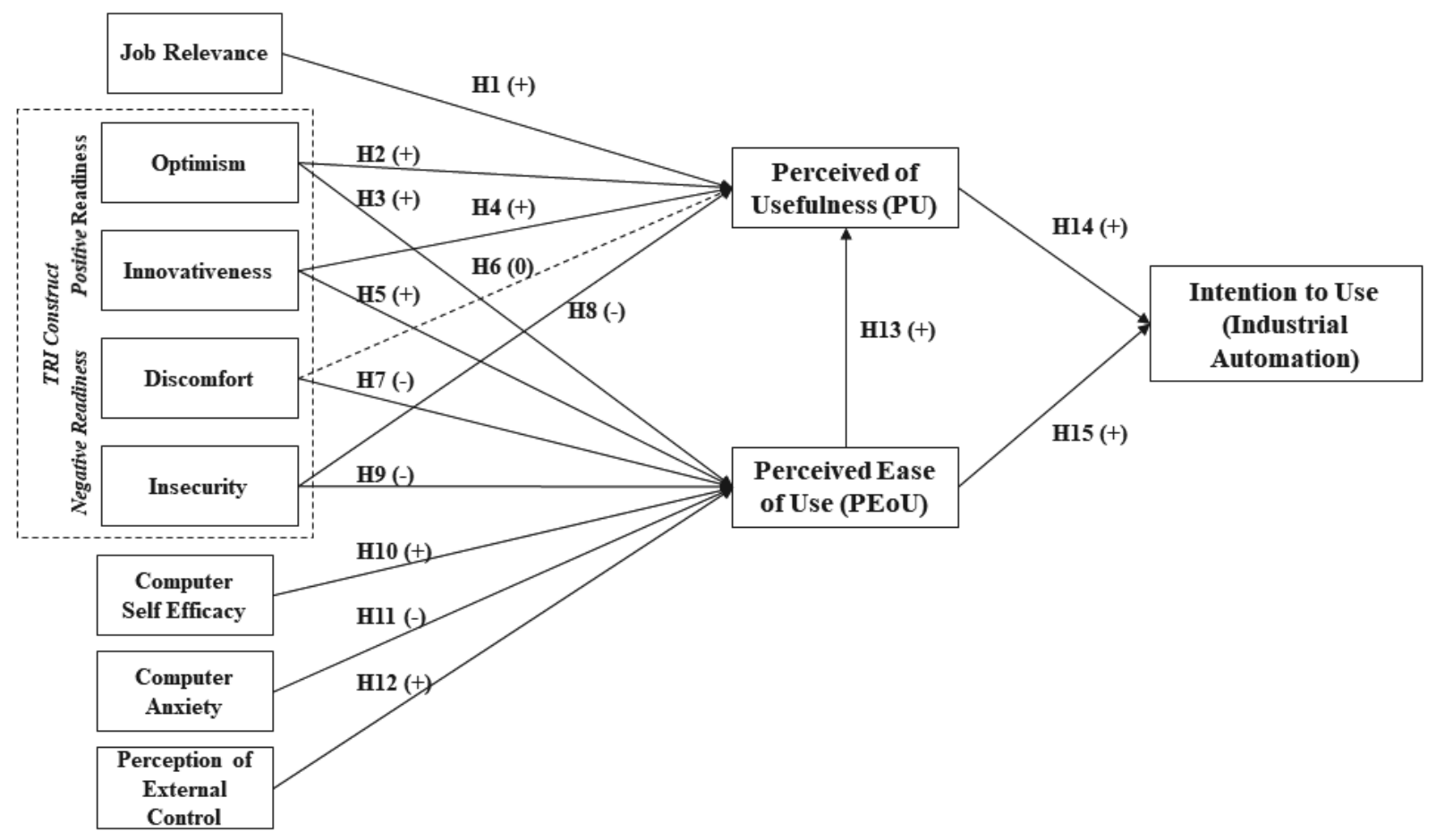

Fig. 1 Conceptual Model of Industrial Automation TRAM with Hypotheses

The PEoU construct denoted the degree to which users observed the effortless usage of systems or technologies [35] and the importance of trust-building among customers [35]. For example, past researchers indicated that the PEoU of IIoT inventions increased user satisfaction and positively influenced the intention to use [35]. Both PU and PEoU significantly influenced the adoption of Industry 4.0. Hence, the following hypotheses were developed:

H13: PEoU has a positive and significant effect on PU.

H14: PU has a positive and significant effect on the Intention to Use

H15: PEoU has a positive and significant effect on the Intention to Use

\section{Methodology}

This study employed the survey technique for data collection, particularly in the context of manufacturing organisations. A pilot test was initially conducted to validate the suggested model constructs. The study data were then obtained through a structured survey questionnaire adapted from the previous studies of
Venkatesh and Bala [35] (TAM 3) and Parasuraman and Colby [40] (TRI 2.0) and was developed accordingly to complement this research. The structured questionnaire involved 42 items using a 10-point Likert scale to provide respondents with more comprehensive response options that reflected individual perspectives. The questionnaire was then distributed to 110 respondents in the target population (manufacturing company employees in Kuala Lumpur, Malaysia). Table 1 below presents the respondents' demographic criteria.

This study aimed to validate the recommended conceptual framework of TAM and TRI constructs using EFA. In Hoque et al. [54, 55], researchers who modified previously-established instruments and items to fit the current research must perform a pilot study using the EFA procedure. In the study context, The pilot study was necessary owing to the socio-economic, racial, and cultural differences of the current study population as opposed to past studies. Hence, some items may no longer be appropriate for this study. On another note, the EFA procedure was implemented on the notion that measurable variables were reduced into fewer latent variables that shared a common variance and were unobservable [56]. 
Tab. 1 Respondents' Profile

\begin{tabular}{lll}
\hline \hline Demographic Criteria & Frequency & $\%$ \\
\hline Gender & & \\
Male & 82 & 74.5 \\
Female & 28 & 25.5 \\
Age & & \\
$18-25$ & 24 & 21.8 \\
$26-35$ & 34 & 30.9 \\
$36-45$ & 35 & 31.8 \\
$46-55$ & 16 & 14.5 \\
Over 55 & 1 & 0.90 \\
Level of Education & & \\
Below High School & 3 & 2.7 \\
High School Diploma & 29 & 26.4 \\
Vocational/Technical de- & 34 & 30.9 \\
gree & 39 & 35.5 \\
Bachelor's Degree & 5 & 4.5 \\
Master's Degree & - & - \\
Doctorate Degree & & \\
Work Experience & & \\
(related to Industrial Auto- & & \\
mation) & & \\
Less than three years & 8 & 7.3 \\
3 - 5 years & 28 & 25.5 \\
6 - 10 years & 32 & 29.1 \\
10 - 15 years & 27 & 24.5 \\
Over 15 years & 15 & 13.6 \\
\end{tabular}

\section{Results and Findings}

This study employed EFA to examine the structural elements of all the study measures. Furthermore, EFA was the most common assessment method to measure internal reliability [56]. On the other hand, the principal component analysis (PCA) was the mostutilised method to indicate variations and detect strong dataset patterns by reducing the dataset dimensionality while maintaining the highest variability [56]. Two distinct EFA procedures employed the PCA extraction method using Varimax Rotation. The first procedure was tested on the 26 items measuring TAM constructs, whereas the second procedure assessed the16 items measuring TRI constructs.

The EFA procedures were expected to produce the study results for i) the Kaiser-Meijer-Olkin mea- sure of sampling adequacy (KMO), ii) the total variance for each construct, iii) the factor loading for every item, and iv) the internal consistency score of the construct through Cronbach's Alpha [54]. The KMO test investigated data adequacy for factor analysis [57] and evaluated the sampling fit for all variables and the variance proportion among variables in the suggested model. A KMO higher than 0.5 indicated acceptable data adequacy for factor analysis [57].

\subsection{The KMO and Bartlett's Test of Sphericity (Bart- lett's Test)}

Tables $2 \mathrm{a}$ and $2 \mathrm{~b}$ indicate Bartlett's significant test result $(\mathrm{P}-$ Value $<0.05)$, whereas the KMO results were 0.518 and 0.578 , thus indicating a higher value than the required 0.5. Overall, both test values (significant Bartlett's Test and $\mathrm{KMO}>0.5$ ) reflected data adequacy [57].

Tab. 2(a) KMO and Bartlett's Test (TAM constructs)

\begin{tabular}{|c|c|c|}
\hline \multicolumn{3}{|c|}{ KMO and Bartlett's Test } \\
\hline \multicolumn{2}{|c|}{ KMO } & .518 \\
\hline \multirow{3}{*}{ Bartlett's Test } & Approx. Chi-Square & 2778.696 \\
\cline { 2 - 3 } & $\mathrm{df}$ & 325 \\
\cline { 2 - 3 } & Sig. & .000 \\
\hline
\end{tabular}

Tab. 2(b) KMO and Bartlett's Test (TRI constructs)

\begin{tabular}{|c|c|c|}
\hline \multicolumn{3}{|c|}{ KMO and Bartlett's Test } \\
\hline \multirow{2}{|c|}{ KMO } & .578 \\
\hline \multirow{3}{*}{ Bartlett's Test } & Approx. Chi-Square & 1143.520 \\
\cline { 2 - 3 } & $\mathrm{df}$ & 120 \\
\cline { 2 - 3 } & Sig. & .000 \\
\hline
\end{tabular}

\subsection{Total Variance Explained}

The total variance explained was an extraction process of questionnaire items to be reduced into a manageable number before further analysis. Specifically, the components with eigenvalues exceeding 1.0 were extracted to different components $[54,55]$. Table 3 reveals that EFA extracted seven components from TAM constructs and four components from TRI constructs with the eigenvalue presented in Tables 3(a) and (b) below. The results demonstrated that the items were categorised into 11 components for further analysis.

Tab. 3(a) Total Variance Explained (TAM constructs)

\begin{tabular}{|c|c|c|c|c|c|c|}
\hline \multicolumn{7}{|c|}{ Total Variance Explained } \\
\hline \multirow{2}{*}{ Component } & \multicolumn{3}{|c|}{ Initial Eigenvalues } & \multicolumn{3}{c|}{ Rotation Sums of Squared Loadings } \\
\cline { 2 - 7 } & Total & $\%$ of variance & Cumulative \% & Total & $\%$ of variance & Cumulative $\%$ \\
\hline 1 & 5.602 & 21.546 & 21.546 & 3.441 & 13.236 & 13.236 \\
\hline 2 & 3.411 & 13.118 & 34.664 & 3.201 & 12.310 & 25.546 \\
\hline 3 & 3.047 & 11.720 & 46.385 & 3.129 & 12.033 & 37.580 \\
\hline 4 & 2.580 & 9.923 & 56.307 & 2.859 & 10.995 & 48.575 \\
\hline 5 & 2.310 & 8.885 & 65.193 & 2.852 & 10.968 & 59.543 \\
\hline 6 & 1.972 & 7.586 & 72.778 & 2.392 & 9.201 & 68.744 \\
\hline 7 & 1.253 & 4.820 & 77.599 & 2.302 & 8.855 & 77.599 \\
\hline
\end{tabular}


Tab. 3(b) Total Variance Explained (TRI constructs)

\begin{tabular}{|c|c|c|c|c|c|c|}
\hline \multicolumn{7}{|c|}{ Total Variance Explained } \\
\hline \multirow{2}{*}{ Component } & \multicolumn{7}{|c|}{ Initial Eigenvalues } & \multicolumn{3}{c|}{ Rotation Sums of Squared Loadings } \\
\cline { 2 - 7 } & Total & $\%$ of variance & Cumulative \% & Total & $\%$ of variance & Cumulative $\%$ \\
\hline 1 & 3.771 & 23.571 & 23.571 & 3.109 & 19.433 & 19.433 \\
\hline 2 & 3.099 & 19.368 & 42.939 & 2.913 & 18.207 & 37.640 \\
\hline 3 & 2.888 & 18.052 & 60.992 & 2.829 & 17.681 & 55.322 \\
\hline 4 & 1.803 & 11.266 & 72.258 & 2.710 & 16.936 & 72.258 \\
\hline
\end{tabular}

Tables 3(a) and (b) also reveal that the total variance explained was $77.599 \%$ (TAM construct) and $72.258 \%$ (TRI construct). Overall, the total variance explained for the study constructs were acceptable (above the minimum requirement of 60\%) [54, 55]. In contrast, values below $60 \%$ indicated item inadequacy in construct measurement.

\subsection{Factor Loading}

Tab. 4(a) Rotated Component Matrix (TAM constructs) Rotated Component Matrix ${ }^{a}$

\begin{tabular}{|c|c|c|c|c|c|c|c|}
\hline & \multicolumn{7}{|c|}{ Component } \\
\hline & 1 & 2 & 3 & 4 & 5 & 6 & 7 \\
\hline JR1 & & & & & & & .911 \\
\hline JR2 & & & & & & & .885 \\
\hline JR3 & & & & & & & .792 \\
\hline CSE1 & & & & .893 & & & \\
\hline CSE2 & & & & .898 & & & \\
\hline CSE3 & & & & .722 & & & \\
\hline \begin{tabular}{|l|} 
CSE4 \\
\end{tabular} & & & & .825 & & & \\
\hline$\overline{\mathrm{CA} 1}$ & \multicolumn{7}{|c|}{ Item to be removed } \\
\hline CA2 & & & & & & .724 & \\
\hline CA3 & & & & & & .803 & \\
\hline CA4 & & & & & & .765 & \\
\hline PEC1 & & & & & .824 & & \\
\hline PEC2 & & & & & .857 & & \\
\hline PEC3 & & & & & .829 & & \\
\hline PEC4 & & & & & .841 & & \\
\hline PU1 & .742 & & & & & & \\
\hline PU2 & .785 & & & & & & \\
\hline PU3 & .865 & & & & & & \\
\hline PU4 & .730 & & & & & & \\
\hline PEoU1 & & .928 & & & & & \\
\hline PEoU2 & & .709 & & & & & \\
\hline PEoU3 & & .942 & & & & & \\
\hline PEoU4 & & .898 & & & & & \\
\hline BI1 & & & .853 & & & & \\
\hline $\mathrm{BI} 2$ & & & .834 & & & & \\
\hline $\mathrm{BI3}$ & & & .878 & & & & \\
\hline
\end{tabular}

Extraction Method: PCA.

Rotation Method: Varimax with Kaiser Normalisation.

a. Rotation converged in 6 iterations.

Job Relevance (JR), Computer Self-Efficacy (CSE), Computer Anxiety (CA), Perceptions of External Control (PEC), Perceived Usefulness (PU), Perceived Ease of Use (PEoU), Behavioral Intention (BI)
Tables 4 (a) and (b) present the factor loading for every item and component, thus indicating the importance of the specific item in construct measurement. As the acceptable value of factor loading was 0.6, items with a factor loading of less than 0.6 should be removed from the study [54, 55]. Resultantly, items CA1 and DS1 (with values below 0.6) was omitted from the questionnaire. The remaining items with factor loadings above 0.6 were retained.

Tab. 4(b) Rotated Component Matrix (TRI constructs)

\begin{tabular}{|c|c|c|c|c|}
\hline \multicolumn{5}{|c|}{ Rotated Component Matrix } \\
\hline & \multicolumn{4}{|c|}{ Component } \\
\hline & 1 & 2 & 3 & 4 \\
\hline OP1 & .898 & & & \\
\hline OP2 & .911 & & & \\
\hline OP3 & .888 & & & \\
\hline OP4 & .742 & & & \\
\hline IN1 & & & .836 & \\
\hline IN2 & & & .876 & \\
\hline IN3 & & & .825 & \\
\hline $\mathrm{IN} 4$ & & & .771 & \\
\hline DS1 & \multicolumn{4}{|c|}{ Item to be removed } \\
\hline $\mathrm{DS} 2$ & & & & .865 \\
\hline DS3 & & & & .879 \\
\hline $\mathrm{DS} 4$ & & & & .863 \\
\hline IS1 & & .879 & & \\
\hline IS2 & & .853 & & \\
\hline IS3 & & .844 & & \\
\hline IS4 & & .806 & & \\
\hline
\end{tabular}

Extraction Method: PCA.

Rotation Method: Varimax with Kaiser Normalisation.

a. Rotation converged in 5 iterations.

Optimism (OP), Innovativeness (IN), Discomfort (DS), Insecurity (IS)

\subsection{Internal Consistency Score (Cronbach's Alpha)}

Finally, this study employed Cronbach's Alpha to assess the internal reliability of the survey items in construct measurement. The reliability analysis was employed to measure the study items under each construct and evaluate the extent to which the items were error-free. Some authors had varying perceptions concerning the acceptance value of Cronbach's Alpha as an indicator of the internal consistency of items. Nevertheless, it was commonly agreed that a Cronbach's 
Alpha of 0.6 and above provided a reliable measure of internal consistency. Furthermore, a score of 0.70 and above indicated that the instrument possessed an excellent reliability standard $[58,59]$. Tables 5 (a) and (b) present the Cronbach's Alpha value for every component. All 11 components demonstrated the Cronbach's Alpha value to be higher than 0.7, thus reflecting high reliability and suitability regarding the selected study items.

Tab. 5(a) Internal Reliability (TAM constructs)

\begin{tabular}{|c|c|c|}
\hline Reliability Statistics \\
\hline Component & N of Items & $\begin{array}{c}\text { Cronbach's } \\
\text { Alpha }\end{array}$ \\
\hline 1 & 4 & 0.928 \\
\hline 2 & 4 & 0.870 \\
\hline 3 & 3 & 0.953 \\
\hline 4 & 4 & 0.858 \\
\hline 5 & 4 & 0.854 \\
\hline 6 & 3 & 0.840 \\
\hline 7 & 3 & 0.834 \\
\hline Total & 25 & \\
\hline
\end{tabular}

Tab. 5(b) Internal Reliability (TRI constructs)

\begin{tabular}{|c|c|c|}
\hline Reliability Statistics \\
\hline Component & N of Items & $\begin{array}{c}\text { Cronbach's } \\
\text { Alpha }\end{array}$ \\
\hline 1 & 4 & 0.894 \\
\hline 2 & 4 & 0.861 \\
\hline 3 & 4 & 0.853 \\
\hline 4 & 3 & 0.867 \\
\hline Total & 15 & \\
\hline
\end{tabular}

Based on the results, the instrument measuring the suggested Industrial Automation Acceptance Model construct involving a combination of 11 components with a specific number of items in every component (40 items in total) was ready to be used. Upon obtaining the study data, a Confirmatory Factor Analysis (CFA) procedure was performed to validate the latent construct. This study then designed the structural model and performed the Structural Equation Modelling (SEM) procedure to assess and verify the study hypotheses and goodness-of-fit in the conceptual model.

\section{Conclusion and Future Work}

This study discussed the technological characteristics implemented in the manufacturing industry, particularly in automation technology, by addressing the current industrial issues. Additionally, a new TAM was developed by augmenting the TAM 3 constructs and TAMs to predict the acceptance of Industry 4.0 among manufacturing employees. Following the EFA result, Bartlett's Test was statistically significant ( $\mathrm{P}-\mathrm{Va}-$ lue $<0.05)$, KMO was above the minimum value (>
$0.5)$, the factor loadings exceeded the minimum threshold of 0.6, and a high Cronbach's Alpha value (> $0.7)$ was achieved. The development and validation of EFA procedures were crucial steps in ensuring that the new instrument was internally consistent and stable across samples. Regarding the study data collection, the recommended minimum sample size followed a 10-to-one ratio of the questionnaire items [60]. Consequently, 40 questionnaire items were designed. A minimum sample size of $40 \times 10=400$ respondents was required from the target population. Upon data collection, an empirical study for the CFA procedure to verify the latent construct before employing SEM was suggested to test the study hypotheses and goodness-of-fit model.

\section{Implications and Suggestions}

Several study implications were indicated following the study results. Theoretically, this study contributed to existing works of literature on technology acceptance by synthesising TAM 3 and TRI 2.0 theories, thus developing a novel TAM in manufacturing. This study also incorporated past studies on technological acceptance with significant insights into adopting Industry 4.0 under TAM 3 and TAMs. Furthermore, the reliability of variables in the suggested model was empirically examined using EFA and Cronbach's Alpha. The KMO test was employed to analyse data adequacy for factor analysis.

Conclusively, this study could become the groundwork in enhancing the adoption of Industry 4.0, particularly in the use of industrial automation technologies. Hence, the study outcome enabled the manufacturing sector to identify and understand the key determinants in designing industrial automation technology processes. The study results could also be considered as valuable input for relevant government bodies in drafting new Industry 4.0 policies, particularly on the industrial automation policy. Following the input, policymakers would be able to formulate better incentives or grants that met the industrial requirements in adopting industrial automation technologies.

Regardless, some study limitations were encountered in this study. As the current study sample was collected from several factory workers in Kuala lumper, Malaysia, the generalisability of the study results might have been compromised. Additionally, this study adopted a cross-sectional research design. Therefore, future studies should consider a longitudinal approach to add value to the recommended conceptual model. Lastly, the current research only emphasised manufacturing employees in the context of Industry 4.0 adoption. Thus, future research may also investigate different staff members, such as the board of directors and CEOs to obtain a sound understanding of the decision-making processes in technological implementation. 


\section{Acknowledgement}

This work was supported under the National Defense University of Malaysia Short Grants UPNM/2020/GPJP/ICT/4.

\section{References}

[1] DRATH, R. AND HORCH, A. (2014) 'Industrie 4.0: Hit or hype? [Industry Forum]', IEEE Industrial Electronics Magazine, 8(2), pp. 56-58.

[2] YIN, Y., STECKE, K. E. AND LI, D. (2018) 'The evolution of production systems from Industry 2.0 through Industry 4.0', International Journal of Production Research. Taylor \& Francis, 56(1-2), pp. 848-861.

[3] AIMAN, M. et al. (2016) 'Jurnal Teknologi Full Paper Industry 4.0: A Review On Industrial Automation And Robotic', 78, pp. 2180-3722.

[4] EROL, S. et al. (2016) 'Tangible Industry 4.0: A Scenario-Based Approach to Learning for the Future of Production', Procedia CIRP. Elsevier B.V., 54, pp. 13-18.

[5] C. J. BARTODZIEJ (2017). "The concept industry 4.0,", Springer, pp. 27-50.

[6] VAIDYA, S., AMBAD, P. AND BHOSLE, S. (2018) 'Industry 4.0 - A Glimpse', Procedia Manufacturing. Elsevier B.V., 20, pp. 233-238.

[7] GERRIKAgOITIA, J. K., UNAMUNO, G., URKIA, E., \& SERNA, A. (2019). Digital manufacturing platforms in the industry 4.0 from private and public perspectives. Applied Sciences, 9(14), 2934.

[8] CASTELO-BRANCO, I., CRUZ-JESUS, F., \& OLIVEIRA, T. (2019). Assessing Industry 4.0 readiness in manufacturing: Evidence for the European Union. Computers in Industry, 107, pp. 22-32.

[9] RANE, S. B., \& NARVEL, Y. A. M. (2019). Redesigning the business organization using disruptive innovations based on blockchainIoT integrated architecture for improving agility in future Industry 4.0. Benchmarking: An International Journal.

[10] WITKOWSKI, K. (2017). Internet of things, big data, industry 4.0-innovative solutions in logistics and supply chains management. Procedia Engineering, 182, pp. 763-769.

[11] WANG, Y., MA, H. S., YANG, J. H., \& WANG, K. S. (2017). Industry 4.0: a way from mass customization to mass personalization production. Advances in Manufacturing, 5(4), pp. 311-320.

[12] FJELDSTAD, Ø. D., \& SNOW, C. C. (2018). Business models and organization design. Long Range Planning, 51(1), pp. 32-39.

[13] JENTSCH D, RIEDEL R, JÄNTSCH A, MÜLLER E. (2013) Factory Audit for Industry 4.0 - Strategic approach for capability assessment and gradual introduction of a smart factory. ZWF Zeitschrift für Wirtschaftlichen Fabrikbetrieb 108: pp. 678-681.

[14] GHOBAKHLOO, M. (2018). The future of manufacturing industry: a strategic roadmap toward Industry 4.0. Journal of Manufacturing Technology Management.

[15] LIERE-NETHELER, K. (2017). Analysis of Adoption Processes in Industry 4.0. In STPIS@CAiSE,pp. 83-89).

[16] ZHONGYI, M., YOUNUS, M., YONGJIN, L. (2011) 'Automated Planning and Scheduling System for the Composite Component Manufacturing Workshop', Eng. Lett.

[17] FRANK, A. G., DALENOGARE, L. S., AYALA, N. F. (2019) 'Industry 4.0 technologies: Implementation patterns in manufacturing companies', International Journal of Production Economics. Elsevier B.V., 210(September 2018), pp. $15-26$.

[18] PWC, P. (2016) 'Industry 4.0: Building the digital enterprise.' 2016 Global Industry 4.0 Survey London, Great Britain.

[19] BAKAR, M. S. A., BIDIN, R. (2014) 'Technology Acceptance and Purchase Intention towards Movie Mobile Advertising among Youth in Malaysia', Procedia - Social and Behavioral Sciences. Elsevier B.V., 130, pp. 558567.

[20] MARANGUNIĆ, N., GRANIĆ, A. (2015) 'Technology acceptance model: a literature review from 1986 to 2013', Universal Access in the Information Society, 14(1), pp. 81-95.

[21] LAI, P. (2017) 'the Literature Review of Technology Adoption Models and Theories for the Novelty Technology', Journal of Information Systems and Technology Management, 14(1), pp. 21-38.

[22] CHARALAMBOUS, G., FLETCHER, S. R., WEBB, P. (2017) 'The development of a Human Factors Readiness Level tool for implementing industrial human-robot collaboration', International Journal of Advanced Manufacturing Technology. 91(5-8), pp. 2465-2475. 
[23] CHARALAMBOUS, G., FLETCHER, S., WEBB, P. (2015) 'Identifying the key organisational human factors for introducing humanrobot collaboration in industry: an exploratory study', International Journal of Advanced Manufacturing Technology, 81(9-12), pp. 2143-2155.

[24] SCHUH, G. et al. (2014) 'Collaboration mechanisms to increase productivity in the context of industrie 4.0', Procedia CIRP. Elsevier B.V., 19(C), pp. 51-56.

[25] NEUGEBAUER, R. et al. (2016) 'Industrie 4.0 - From the Perspective of Applied Research', Procedia CIRP, 57, pp. 2-7.

[26] WITKOWSKI, K. (2017) 'Internet of Things, Big Data, Industry 4.0 - Innovative Solutions in Logistics and Supply Chains Management', Procedia Engineering. The Author(s), 182, pp. $763-$ 769.

[27] ZHONG, R. Y. et al. (2017) 'Intelligent Manufacturing in the Context of Industry 4.0: A Review', Engineering. Elsevier LTD on behalf of Chinese Academy of Engineering and Higher Education Press Limited Company, 3(5), pp. 616-630.

[28] KOZIK, R., CHORAŚ, M. (2013) 'Current cyber security threats and challenges in critical infrastructures protection', 2013 2nd International Conference on Informatics and Applications, ICIA 2013, pp. 93-97.

[29] RÜBMANN, M. et al (2015) 'Future of Productivity and Growth in Manufacturing', Boston Consulting, (April).

[30] LANDHERR, M., SCHNEIDER, U., BAUERNHANSL, T. (2016) 'The Application Center Industrie 4.0 - Industry-driven Manufacturing, Research and Development', Procedia CIRP. Elsevier B.V., 57, pp. 26-31.

[31] HORITA, F. E. A. et al. (2017) 'Bridging the gap between decision-making and emerging big data sources: An application of a model-based framework to disaster management in Brazil', Decision Support Systems, 97, pp. 12-22.

[32] KAWAKATSU, H., YAMANAKA, N., KATO, K. (2019) 'Visualisation of Change in Employee Morale during Organizational Innovation', 0958, pp. 3-7.

[33] MÜLLER, J. M., KIEL, D., VOIGT, K. I. (2018) What drives the implementation of Industry 4.0? The role of opportunities and challenges in the context of sustainability', Sustainability (Switzerland), 10(1).
[34] ISKANIUS, P. (2009) 'Risk Management in ERP Project in the Context of SMEs 2. Resource Allocation 3. Succes Criteria 4. Interesting 5. PPM PIMS', Engineering Letters, (November).

[35] VENKATESH, V., BALA, H. (2008) 'Technology acceptance model 3 and a research agenda on interventions', Decision Sciences, 39(2), pp. 273-315.

[36] DAVIS, F. D. (1989) 'Perceived usefulness, perceived ease of use, and user acceptance of information technology', MIS quarterly. JSTOR, pp. 319-340.

[37] TARHINI, A. et al. (2015) 'A Critical Review of Theories and Models of Technology Adoption and Acceptance in Information System Research', International Journal of Technology Diffusion, 6(4), pp. 58-77.

[38] INDRATI, A. et al. (2012) Validity of the technology acceptance model (tam): a sensemaking perspective', Ijms, 6(1), pp. 99120.

[39] A., P. (2000) 'Technology Readiness Index (TRI): A Multiple item Scale To Measure Readiness To Embrace New Technologies', Journal Of Service Research, 2:307(May).

[40] PARASURAMAN, A., COLBY, C. L. (2015) 'An Updated and Streamlined Technology Readiness Index: TRI 2.0', Journal of Service Research. SAGE Publications Inc., 18(1), pp. 59-74.

[41] LIN, C. H., SHIH, H. Y., SHER, P. J. (2007) 'Integrating technology readiness into technology acceptance: The TRAM model', Psychology and Marketing, 24(7), pp. 641-657.

[42] HALLIKAINEN, H., LAUKKANEN, T. (2016) 'How technology readiness explains acceptance and satisfaction of digital services in B2B healthcare sector?', in Pacific Asia Conference On Information Systems (PACIS). Association For Information System.

[43] SHIN, S., LEE, W. J. (2014) 'The effects of technology readiness and technology acceptance on NFC mobile payment services in Korea', Journal of Applied Business Research, 30(6), pp. 1615-1626.

[44] LARASATI, N. (2017) 'Technology Readiness and Technology Acceptance Model in New Technology Implementation Process in Low Technology SMEs', International Journal of Innovation, Management and Technology, 8(2), pp. 113-117. 
[45] YI, Y., TUNG, L. L., WU, Z. (2003) 'Incorporating Technology Readiness (TR) Into TAM : Are Individual Traits Important to Understand Technology Acceptance ?', DIGIT 2003 Proceedings, pp. 1-27.

[46] WEI, K. AND RAM, J. (2016) 'Perceived usefulness of podcasting in organizational learning: The role of information characteristics', Computers in Human Behavior. Elsevier Ltd, 64, pp. 859-870.

[47] SOHN, S. (2017) 'A contextual perspective on consumers' perceived usefulness: The case of mobile online shopping', Journal of Retailing and Consumer Services. Elsevier Ltd, 38(January), pp. 22-33.

[48] OPITZ, N. et al. (2012) 'Technology acceptance of cloud computing: Empirical evidence from German IT departments', Proceedings of the Annual Hawaii International Conference on System Sciences, pp. 1593-1602.

[49] PARVEEN, F. AND SULAIMAN, A. (2008) 'Technology complexity, personal innovativeness and intention to use wireless internet using mobile devices in Malaysia', International Review of Business, 4(5), pp. 1-10.

[50] GODOE, P. AND JOHANSEN, T. S. (2012) 'Understanding adoption of new technologies: Technology readiness and technology acceptance as an integrated concept', Journal of European Psychology Students, 3, pp. 38.

[51] HACKBARTH, G., GROVER, V., YI, M. Y. (2003) 'Computer playfulness and anxiety: Positive and negative mediators of the system experience effect on perceived ease of use', Information and Management, 40(3), pp. 221-232.

[52] IGBARIA, M., SCHIFFMAN, S. J., WIECKOWSKI, T. J. (1994) 'The respective roles of perceived usefulness and perceived fun in the acceptance of microcomputer technology', Behaviour and Information Technology, 13(6), pp. 349-361.

[53] LU, H. P., HSU, C. L., HSU, H. Y. (2005) 'An empirical study of the effect of perceived risk upon intention to use online applications', Information Management and Computer Security, 13(2), pp. 106-120.

[54] HOQUE, A. S. M. M. et al. (2017) 'Social Businecs Efficiency: Instrument Development and Validation Procedure using Structural Equation Modelling', International Business Management, 11(1), pp. 222-231.
[55] HOQUE, A. S. M. M., AWANG, Z. (2016) Exploratory Factor Analysis of Entrepreneurial Marketing: Scale Development and Validation in The SME Context of Bangladesh', Proceedings of the International Social Sciences and Tourism Research Conference 20-22 April 2016, (April), pp. 22-38.

[56] BARTHOLOMEW, D. J., KNOTT, M., MOUSTAKI, I. (2011) Latent variable models and factor analysis: A unified approach. John Wiley \& Sons.

[57] YONG, A. G., PEARCE, S. (2013) 'A Beginner's Guide to Factor Analysis: Focusing on Exploratory Factor Analysis', Tutorials in Quantitative Methods for Psychology, 9(2), pp. 7994.

[58] HOQUE, A. S. M. M., AWANG, Z. BIN (2019) 'Does gender difference play moderating role in the relationship between entrepreneurial marketing and bangladeshi SME performance?', Accounting, 5(1), pp. 35-52.

[59] HOQUE, A. S. M. M. et al. (2018) 'Ramification of crowdfunding on Bangladeshi entrepreneur's self-efficacy', Accounting, 4, pp. 129-138.

[60] HAIR, J. F. et al. (1998) Multivariate data analysis. Prentice hall Upper Saddle River, NJ.

[61] KELLNER, T. et al. (2020) 'Assessment of Readiness for Industry 4.0 Implementation in Ceramic Industry', Manufacturing Technology, 20(6), pp. $763-770$

[62] SUJOVÁ, E., STř̃HAVKOVÁ, E. AND ČIERNA, H. (2018) 'An Analysis of the Assembly Line Modernization by Using Simulation Software', Manufacturing Technology, 18(5), pp. 839-845.

[63] ULEWICZ, R. AND MAZUR, M. (2019) 'Economic Aspects of Robotization of Production Processes by Example of a Car Semi-trailers Manufacturer', Manufacturing Technology, 19(6), pp. 1054-1059.

[64] JUNG, J. et al. (2021) 'Exploration of sharing accommodation platform airbnb using an extended technology acceptance model', Sustainability (Switzerland), 13(3), pp. 1-16.

[65] KIM, E. J., KIM, J. J., HAN, S. H. (2021) 'Understanding student acceptance of online learning systems in higher education: Application of social psychology theories with consideration of user innovativeness', Sustainability (Switzerland), 13(2), pp. 1-14. 
[66] ZHONG, Y., OH, S., MOON, H. C. (2021) 'Service transformation under industry 4.0: Investigating acceptance of facial recognition payment through an extended technology acceptance model', Technology in Society. Elsevier Ltd, 64(September 2020), p. 101515.

[67] ZHAO, Y. et al. (2020) 'Do cultural differences affect users' e-learning adoption? A meta-analysis', British Journal of Educational Technology.

[68] ALFADDA, H. A., MAHDI, H. S. (2021) 'Measuring Students' Use of Zoom Application in Language Course Based on the Technology Acceptance Model (TAM)', Journal of Psycholinguistic Research. Springer.
[69] ALI, S. et al. (2021) 'Consumer adoption of online food delivery ordering (Ofdo) services in pakistan: The impact of the covid-19 pandemic situation', Joumal of Open Innovation: Technology, Market, and Complexity, 7(1), pp. 1-23.

[70] SHIM, H. S., HAN, S. L., HA, J. (2021) 'The effects of consumer readiness on the adoption of self-service technology: Moderating effects of consumer traits and situational factors', Sustainability (Switzerland), 13(1), pp. 1-17.

[71] QASEM, Z. (2021) 'The effect of positive TRI traits on centennials adoption of try-on technology in the context of E-fashion retailing', International Journal of Information Management. Elsevier Ltd, 56(March 2020), p. 102254. 